\title{
Influence of Root-Seeking Culture on the Development of Tourism in Henan Province
}

\author{
Li-Xia ZHAO \\ School of Literature and Law, Nanyang Institute of Technology, No.80. \\ Changjiang Avenue, Wolong District,473000, Henan, P.R.China
}

z|z|xz|@163.com

Keywords: Family root-seeking culture, Henan Province, Tourism.

\begin{abstract}
As an important birthplace of Chinese civilization, Henan Province has a profound background of family root-seeking culture. In this paper, ways to combine the rich family root-seeking culture with the development of tourism in Henan Province are discussed, and taking family root-seeking culture in Gushi County as a typical case, the present situation and potential of the development of Henan's family root-seeking culture are explored.
\end{abstract}

\section{Introduction}

In the long history the Central Plains culture, various places in Henan Province have accumulated rich cultural resources, and the root seeking culture has been paid more and more attention by all walks of life, which has endowed Henan Province with an exceptional advantage to develop its family root-seeking culture. Today, when tourism has taken up an increasingly important proportion in the economic development of all provinces, to give full play to the soft power of family root-seeking culture, to promote the integration and development of family root-seeking culture and tourism industry in Zhengzhou, to explore the approaches to develop Henan's cultural tourism industry by using family root-seeking culture resources, and to realize the mutual transformation of cultural value and economic benefits, are of far-reaching influence and significance to the future development of Henan's tourism industry.

\section{Development of Henan's Family Root-Seeking Culture as the Tourist Resources -- A Case Study of Gushi County}

If Henan is to be said a major province for its development of family root-seeking cultural tourism resources, then that of Gushi County can be considered as a banner and a positive example. In recent years, focusing on the advantage of family root-seeking culture resources, Gushi County has vigorously implemented the project of Let Family Root Culture Be Popular in Gushi, in accordance of which, the regional economy should adhere to the overall development directed by the family root-seeking culture, build cultural brand through root-seeking movements and intensive researches, promote family root-seeking culture and economy, and highlight the unique characteristics of Gushi County. Therefore, the consolidation, excavation, protection and development of the family root-seeking culture have been strengthened, and the integration of family root culture and development of industrial economy has also achieved gratifying results.

First of all, Gushi County has launched a county-widestudy on the family root-seeking culture. Regarding the Research Office of Historical Records as the backbone, Gushi County, by mobilizing all concerning parties, has collected the systematic data of surnames, migrants and root-seeking literature, and established extensive exchanges and cooperation with relevant academic circles both at home and abroad. In October 2003, Gushi, Fujian and Taiwan Root Seeking and Gushi Tourism Resources Development Seminar was held in Gushi County, and more than 40 experts and scholars from and outside the province participated in the event and carried out an in-depth discussion on values of root-seeking culture resources and its development. From 2008 to 2011, the Symposium on the Relationship between Gushi and Fujian and Taiwan was held for four successive years. During which period, the experts and scholars both at home and abroad were invited to study the 
value and utilization of root-seeking resources in Gushi County, and three volumes of the Relationship between Gushi and Fujian and Taiwan were produced, thus a detailed and solid basis for descendants of domestic and overseas migrants to seek roots and visit ancestors in Gushi County was provided since then. With the organic combination of the development of family root-seeking culture and the the protection of excellent traditional culture, excavation, documentation and protection of intangible cultural heritages, such as folk opera Guo Dingxiang, flower-lifting dance, Huagudeng dance, land boat dance, etc.,have been gradually increased.

Secondly, the cultural scenicspots are actively exploited. With the guidance of the developing family root-seeking culture, some cultural heritages that have been renewed are Chen Yuanguang's Ancestral Shrine, Anshan Temple, Root-seeking Building of Tang Dynasty, etc., while those have been restored and expanded are Wang Shenzhi's Former Residence, Zheng Chenggong' Cemetery, Shi's Ancestral Shrine, etc.. The newly built venues featured family root-seeking culture include the only root-seeking museum themed by surnames, Chenggong Square and family root-seeking culture park. In addition, the supporting facilities, such as Guobin, Yuanguang, Victoria and other hotels, as well as west Jiuhua Mountain, Huayang Lake and other star scenic areas, are set. The construction of several major roads, such as Wang Shenzhi Avenue, Chenggong Avenue, etc., is ongoing. The promotion of traffic, the creation of cultural atmosphere and the construction of supporting facilities, have disseminated the home culture of overseas Chinese and is particularly convenient for citizens, while rendering the charm of family root-seeking culture. The verve of Gushi as a famous cultural city gradually appears.

Thirdly, the exchanges of family root-seeking culture should be enhanced. Relying on the platform of family root-seeking culture, Gushi County makes full use of advantages of cultural exchange; pays particular attention to personnel and academic exchanges and commemorative activities with Fujian, Taiwan and other regions; participates in the major events, such as 130th Anniversary of Po Chiak Keng and First International Fellowship Conference for Sacred Founder of Zhangzhou, 600th Anniversary of Zheng He's Voyage to the West and World Chinese Reunion. Among the cultural activities in Fujian, Taiwan and the Central Plains (Gushi), the one carried out in Taiwan was well received by all Taiwanese and started an upsurge of family root-seeking culture in Taiwan, which contributed to the exchanges and cooperation between both sides of the Taiwan Straits. Gushi also held three sessions of family root-seeking culture festivals in the Central Plains (Gushi)successfully, and achieved political, economic and cultural benefits. Through the cultural festivals and exchange activities, Gushi County has made friends from all walks of life both at home and abroad, so as to strengthen the connections with overseas regions and developed areas of China's coastal provinces, and promote the brand of the hometown of Chinese people, the native place of Fujianese and Taiwanese, enhance the root-based force of the overseas Chinese, and highlight its position as the birthplace of family root-seeking culture.

Tourism economy has not only become a new growth point and booster of its economic development, but also made positive contributions to improving the overall image of Gushi. For example, develop ecological tourism relying on ecological resources; carry out root-seeking tours based on its position as hometown of overseas Chinese in the Central Plains; deepen patriotism education by excavating the revolutionary resources; and uphold Buddhist culture depending on the Buddhist shrine-Jiuhua Mountain. Two tourist routes with the theme of root-seeking have been launched successfully, namely one-day tour in the East and suburban leisure tour. It can be said that relying on family root-seeking culture, the entire tourism industry of Gushi County has been developed continuously and rapidly.

\section{Ways to Promote Tourism based on Family Root-Seeking Culture}

To carry forward family root-seeking culture and to promote its distinctive development vigorously are important ways to expand Henan's tourism industry. According to the requirements of basic goals that the cultural connotation of the Central Plains and the cohesion of all Chinese all over the world are enhanced through the excavation of cultural resources, such as Chinese surnames, evolution of characters, Kung Fu culture and Xuanyuan's (an ancient emperor) hometown, Henan's 
cultural tourism should be built into an important carrier for the common spiritual home of Chinese nation, a window to display and experience Chinese history and civilization, a bridge for all Chinese descendants all over the world to seek roots, a demonstration for the development and utilization of Chinese historical and cultural resources, a new highland of the development of Chinese contemporary culture and the base for Chinese culture to go global. And the family root-seeking culture is not only the core of Central Plains culture, but also the essence of China's historical and cultural inheritance and innovation. Therefore, based on the above goals, the strategic orientation of the development of cultural resources in the Central Plains Economic Zone is to combine the protection of national characteristics, the inheritance of intangible cultural heritages, the exploration of humanities and natural resources, and the construction of experimentation areas for cultural heritages, thus building the cultural base of Chinese surnames and carrying forward the gene of Chinese nation.

In order to give full play to the guiding role of the strategic policies, the cultural tourism in Henan Province should be closely related to the theme of family root-seeking culture. And on the path of development, the four drives, namely project, brand, innovation and service, should be paid particular attention to, so that the protection and the exploration of cultural resources can be pushed forward and become the centerpiece of industrial innovation.

The first impetus is project implementation. Centering on the root culture, that is the core of Chinese history and civilization, the projects to promote family root-seeking culture in the Central Plains and to implement root-seeking strategies, are able to lead the protection, the development and the utilization of cultural resources in the Central Plains Economic Zone.

Based on the cultural resources in Henan Province, the protection base of intangible cultural heritages with family root-seeking culture as its main body is established. In Henan Province, there are 83 national intangible cultural heritage projects and more than 200 provincial intangible cultural heritage projects, which are closely linked with the family root-seeking culture. These projects cover a variety of contents and types. Through the construction of protection parks, thematic museums, exhibition centers and inheritance bases for intangible cultural heritages, the forms to express and spread family root-seeking culture have been significantly enriched, and its cohesion, attractiveness and international competitiveness have also been strengthened, which provide support for the development of characteristic cultural industries and the strategy of going global. Depending on the construction of intangible cultural heritage bases, the tourism is able to design the special chain project of tourism industry.

Relying on the construction of the national protected areas, the ones that publicize family root-seeking culture are not only the carriers of the brilliant achievements of Chinese history and civilization, but also the living fossils of family root-seeking culture in ancient times. The purposes of protecting, managing and using the great ruins of cultural zones in the Central Plains are to realize the harmonious symbiosis between the historical and cultural heritages and the family root-seeking culture, and attach importance to the application and display of cultural symbols in the construction of experience areas of ancient cultures. These cities will be built into the largest group of ancient cities in China, which is planned to become the experience area of ancient cities featuring family root-seeking culture on the basis of strengthening cultural innovation and displaying Chinese ancient cities.

Based on the advantages of root culture, the construction projects, including the museums of Chinese surnames, the cultural square of family names, the tower of Chinese surnames, the tablets of historical celebrities in the Central Plains, etc., are carried out, the cultural research institutions focusing on Chinese classic culture and surname culture are established, and the academic highland of family root culture is formed. All these have laid a solid theoretical foundation for the sustainable development of Henan's tourism industry.

The second one to be discussed is the brand drive, which means to earn the fame of culture-oriented tourism.

The ways to consolidate the tourist brand of the root of Chinese civilization, are to build the brand of ancient culture by enhancing the positions of the cultural heritages, such as the tomb of $\mathrm{Fu}$ 
Hsi (one of the Three Sovereigns) in Huaiyang, the hometown of Emperor Huang (one of the legendary rulers) in Xinzheng, the tomb of Emperor Huang in Lingbao, as well as the tombs of Zhuanxu and Ku (two legendary monarchs in ancient China); and taking advantage of the legend that the Three Sovereigns and Five Emperors are the common forefathers of all Chinese and their surnames, to build specific bases for formal visits. Therefore, the image of nationwide tourist county for family root-seeking culture is created

Making full use of geographical advantages, for example, hometown and tomb of Jiang Taigongb (one of the most famous statesmen and strategists in Chinese history) lies in Weihui, Zhou Gong (an outstanding statesman, strategist, thinker and educator in the early Western Zhou Dynasty)Temple is located in Luoyang, place where Emperor Wen (father of the first king of Zhou Dynasty) deduced the Book of Changes is Tangyin, and Temple of Emperor Wu (founder of Zhou Dynasty) stands in Huojia, etc., as well as the historical facts that Jiang Taigong is the forefather of people whose surnames are Jiang, Lv, Lu, Qiu, Gao, Qi, etc., and many other surnames are derived from Ji family, the Henan's brand of root-seeking tourism is publicized.

The capital of Shang Dynasty is located in Zhengzhou, Anyang and other places, so there are 67 surnames related to Shang; due to the fact that the capital of Zheng State lies in Xinzheng, there are 145 surnames related to Zheng; the capital of Wei State sits in Qixian County and Huaiyang, therefore there are 163 surnames related to Wei; and Song State sets its capital in Shangqiu, as a consequent, there are 227 surnames related to Song. The unique advantage of being the birthplace of above surnames, is beneficial to dig the regional cultural tourism resources, set up the demonstration park of ancestral surnames, and build the tourist brand of family root-seeking culture.

Heluo and Gushi areas are the native places of migrants to Hakka areas. People, who share more than 70 surnames that are related to Heluo and Gushi, have become the main part of the Hakka ethnic group in Fujian and Taiwan. On the basis of the self-identity as offspring of Heluo and Gushi, it is necessary to build up the park of the origin of Hakka surnames, and to become known nationwide as the root of a community called Hakka.

Another driving force is service. In the protection, development and utilization of family root-seeking culture in Henan, it is a must to accelerate the construction of supporting services related to tourism industry, strengthen the service functions of each tourism base, change the contents, quality, modes, procedures and attitude of services, and clearly divide the responsibilities and the liabilities of tourism departments at all levels. The specific plan is to establish a long-term mechanism to enhance the quality of tourism service and create a good environment for tourism industries. Henan Province should, first of all, vigorously promote the civilization construction of tourist cities and tourist attractions, actively carry out 100 Outstanding Hotels, 100Travel Agencies of Integrity, 100Excellent Tour Guides and other contests, firmly uphold the service concept of modern cultural tourism, and improve the soft environment of tourism in Henan with quality services; secondly, build the systems of complaint monitoring and network review, set up the data base of tourism related enterprises and personnel, and strengthen the daily supervision, the regular publicity and the dynamic management through the network review platform; thirdly, standardize the market order, control the malignant price competitions and disorderly competition, thus building an open, competitive, standardized and orderly market system; fourthly, increase penalties for negative events that are revealed by tourists and news reports; finally, push the evaluations of tourism facilities and service quality forward, and upgrade the image of Harmonious Henan, Credible Tourism, in the hope of improving tourists' satisfaction.

\section{Value of the Family Root-Seeking Culture in the Tourism of Henan Province}

With the further construction of the Central Plains Economic Zone, Henan's tourism industry is facing a promising opportunity for development. In the advancement of tourism, the root-seeking tourism has become increasingly important. In the future planning, tourism in Henan Province should put more efforts to cultivate family root-seeking culture and adopt scientific and reasonable strategies for further development, thus making the family root-seeking culture a key part of 
tourism in Henan Province, which is of far-reaching value for Henan's cultural tourism to go global and create a brand with its own characteristics.

\section{Self-Identity}

The family root-seeking culture of the Central Plains is colorful and rich. From the current situation, many of the cultural resources, such as Kwangju Gushi, Taiwan village and tomb of Fu Hsi, are unique in the whole country, therefore, the connotation of the family root-seeking culture in the Central Plains is both unique and rich. As mentioned above, the most abundant content of the family root culture is that the Central Plains is hometown of the very first ancestor of humanity. The ancestral affinity and the homeland consciousness refer to the ancestor of humanity and the spiritual ascription of Chinese nation respectively. In terms of the importance that is attached to family ethics by Chinese traditional culture, the first ancestor of the Chinese nation has the functions of affinity and self-identity. Seen from the perspectives of traditional culture, especially the deep love for hometown, the spiritual home of the Chinese nation is also the common home for Chinese people throughout the world, so the root culture of Central Plains has the function of maintaining and identifying the feelings of all Chinese on the planet. Since the number of daily visitors to the fair held in Fu Hsi tomb every February $2^{\text {nd }}$ has reached hundreds of thousands, and the ritual ceremony taken place in Xinzheng to memorize Emperor Huang is well organized on each Tomb-sweeping Day, the root culture has been boasting Henan as a homeland and sacred place for the global Chinese.

\section{Cohesion}

The resources of family root-seeking culture in the Central Plains are inherently integrated. From the overall situation of it, the first ancestorof Chinese people, the birthplace of surnames, the spiritual home of Chinese nation, the Taiwan village and the new emigrants are all the manifestations of root culture. From the point of view of the cultural ecology, it is found out that, the ancestral affinity have been always there, the clan relations and spiritual power will be strengthened with the opening up of the society, the ties between relatives who share the same surnames are discovered, and the fellowship is the spirit that leads the whole nation in the new era. The root-seeking culture in the Central Plains is in a state of continuous change and natural integration. From the perspective of the inheritance and the innovation of Chinese traditional civilization, the various components of the family root-seeking culture need to be not only inherited continuously, but also integrated with each other. This trend of integration plays a strong cohesive effect. For example, in the first Immigration Cultural Festival of South-to-North Water Transfer Project, villagers, who moved to Qinghai Province, Hubei Province, Xinzheng City and Zhengzhou City from Zhejiang Province and Sichuan Province, were gathered together. The culture festival has built a bridge for the exchanges between people from Henan, Fujian and Taiwan, so that many Taiwanese are able to seek for their family roots. The annual ritual ceremony of the Emperor Huang also touches the hearts of the Chinese people all over the world. Therefore, whether it is seen as a whole or as several parts, the family root culture has strong cohesive effect.

\section{Brand Creation}

The root-seeking culture of the Central Plains has a symbolic significance. The main difference between it and other regional cultures is its origin and continuity. The ancestral affinity, such as Fu Hsi Temple Fair, has been going on for thousands of years. Clan relations, the origin of surnames, is an important symbol to verify that Chinese civilization has not been interrupted at all. A lofty tree must have its root, the running water must have its source. Chinese surnames have existed for six thousand years since Fu Hsi determined his surname. The attachment to the homeland embodies the historical complex of heading north to the Central Plains. As an old saying goes, food is the first necessity of people, and the Central Plains is still the granary of China. Heading north to the 
Central Plains is a realistic choice. The Taiwan Village is a copy of root-seeking activities from the Central Plains to Taiwan Province, and the trend of new migrants is a great innovation since the founding of new China. The foundation of cultural brand building is the existence of symbolic culture.

\section{Conclusions}

In a word, the publicity and opening of root culture is of great importance in accelerating the transformation of tourism from attractions to cultures in Henan Province. The long-standing root culture is a priceless treasure of Henan's tourism industry. With the continuous activation of the dust-laden historical and cultural resources, and the launch of a series of cultural tourism projects with the characteristics of root culture, the ideal of pushing Henan's tourism to a broader stage will eventually be realized.

\section{Reference}

[1] Ryan C. Tourism and cultural proximity examples from New Zealand. Annals of Tourism Research 2002; 29(4):952-971

[2] Dyer P, Aberdeen L, et al. Tourism impacts on an Aus-tralian indigenous community: a Djabugay case study. Tourism Management 2003; 24(1): 83-95

[3] E. Breitmaier, W. Volelter, Carbon-13 NMR Spectroscopy, 3rd ed., VCH, New York, 1989: 192

[4] HU GW. Modern Interpretation of Farming Culture. Forum on Chinesr Culture ,2009(S2):215-218 